\title{
Pain Sensation and Long-term Suffering due to Chronic Pain in Patients with Rheumatoid Arthritis: Mediating Role of Self-efficacy
}

\begin{abstract}
Background and Objective: the purpose of this study is to investigate the mediating role of self-efficacy as a cognitive factor in the relationship between pain sensation and long-term suffering.

Materials and Methods: This is a descriptive correlational study. The statistical population of the study included all patients with chronic pain with Rheumatoid Arthritis referring to 11 clinics and private and governmental centers specialized in chronic pain in Tehran and Karaj in a specified time interval (Between Nov2015 and May 2016). 399 patients ( 257 women and 142 men) were selected via accessible sampling. The sensory pain index of the McGill pain scale, the Pain Discomfort Scale (PDS) and the Pain Self-efficacy Questionnaire (PSEQ) were used to collect the data. Data were analyzed by structural equation modeling (SEM).

Results: The results showed that pain sensation and Self-efficacy are considered as good predictors of long-term suffering. Based on the findings of the structural equation modeling, there are significant and a positive causal relationship between pain sensation, self-efficacy and long-term suffering and the mediating role of self-efficacy in the relationship between pain sensation and long-term suffering has been confirmed $(P<0.05)$.

Conclusion: The result of this research, in addition to conceiving long-term suffering, it can be helpful in identifying one of the cognitive-emotional factors of long-term suffering, providing more adaptive strategies for people with in prevention and treatment and health promotion.

Keywords: Pain sensation, Self - efficacy, Long-term suffering

Paper Type: Research Article.
\end{abstract}

Citation (Vancouver): Nejati A, Ahadi H, Meschi F, Seirafi M, Kraskian Mojembari A. Pain Sensation and Long-term Suffering due to Chronic Pain in Patients with Rheumatoid Arthritis: Mediating Role of Self-efficacy. Iran J Health Educ Health Promot. Spring 2020;8(1):10-22. [Persian]

- Citation (APA): Nejati A., Ahadi H., Meschi F., Seirafi M., Kraskian Mojembari A. (Spring 2020). Pain Sensation and Long-term Suffering due to Chronic Pain in Patients with Rheumatoid Arthritis: Mediating Role of Self-efficacy. Iranian Journal of Health Education \& Health Promotion., 8(1), 10-22. [Persian]
Amin Nejati

Graduated Ph.D in Health Psychology, Karaj Branch, Islamic azad university, Karaj, Iran.

Hasan Ahadi

* Professor, Department of Health Psychology, Karaj Branch, Islamic azad university, Karaj, Iran. (Corresponding Author).Email: drhahadi5@gmail.com

Farhnaz Meschi

Assistant Professor, Department of Health Psychology, Karaj Branch, Islamic azad university, Karaj, Iran.

Mohammad Reza Seirafi Assistant Professor, Department of Health Psychology, Karaj Branch, Islamic azad university, Karaj, Iran.

Adis Kraskian Mojembari Assistant Professor, Department of Health Psychology, Karaj Branch, Islamic azad university, Karaj, Iran.

Received: 02 January 2019 Accepted: 08 September2019

Doi: 10.29252/ijhehp.8.1.10 


\section{حس درد و رنج دراز مدت ناشى از درد مزمن در بيماران مبتلا به روماتوئيد آرتريت : نقش واسطه اى خودكارآمدى}

دانث آمرخته دكترى تخصصى روانشناسى سلامت

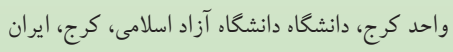

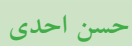
استاد، كروه روانشناسى سلامت واحد كرج دانشكاه آزاد اسلامى، كرج، ايران(نويسنده مسئول): drhahadi5@gmail.com

$$
\text { فرحناز مسجى }
$$

استاديار، كروه روانشناسى سلامت واحد كرج دانشكاه آزاد اسلامى، كرج، ايران

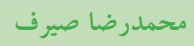

استاديار، كروه روانشناسى سلامت واحد كرج درف دانشكاه

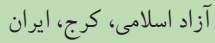

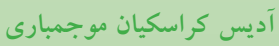

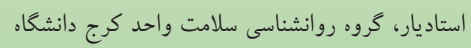

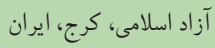

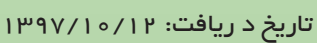

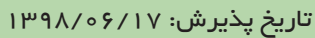

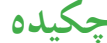

زمينه و هدف: هدف يزوهش حاضر بر رسى نقش واسطه اى خود كار آمدى در رابطه بين حس درد درد و رنج

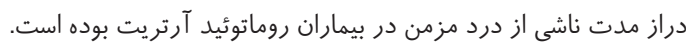

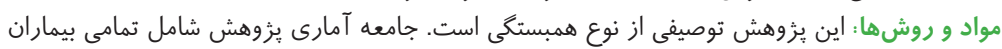

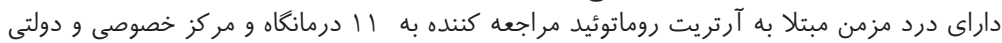

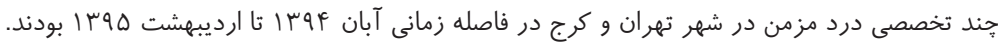

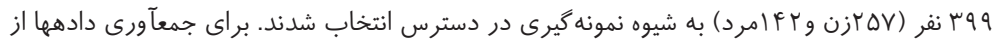

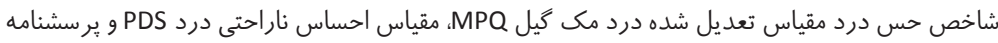

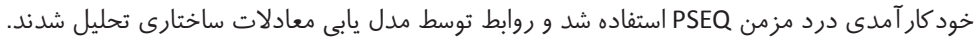

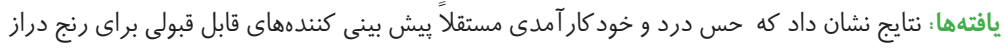

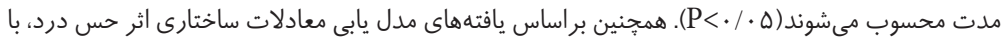

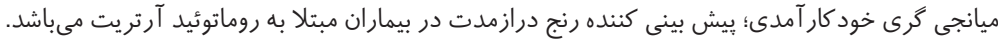

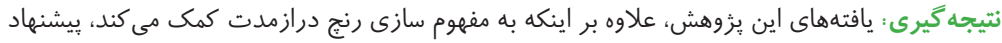

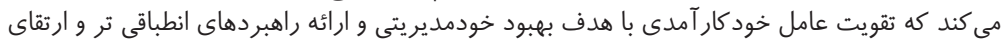

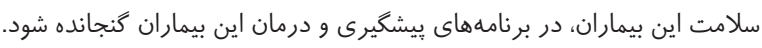

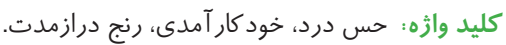
نوع مقاله : مطالعه يزوهشى.

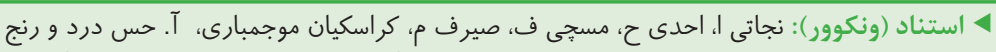

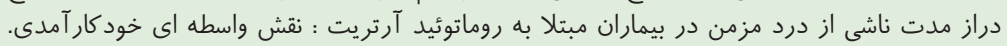

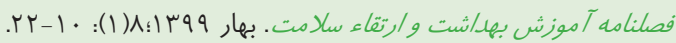

> استناد (APA): نجاتى، امين؛ احدى، حسن؛ مسجى، فرحناز ؛ صيرف، محمدرضا؛ كراسكيان موجمبارى،

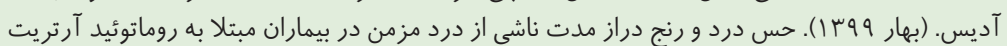

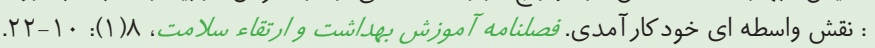


زنان دو تا سه برابر مردان به اين بيمارى مبتلامىشوند (9). علائم

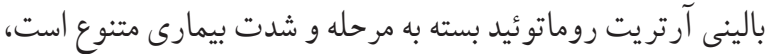
با اين حال علايم شايع آن شامل درد، تورم، گرمى و قرمزى مفاصل

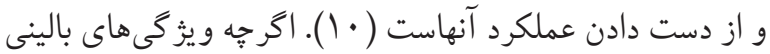
اوليه RA شامل درد، تورم و افت عملكرد فيز يكى است؛ امّا ادراك درد / نار احتى و رنج درازمدت ويث كى اصلى آن و ناخوشايندترين نشانه آن براى بيماران محسوب مى نىود و كه به تنهايى مى دوراند جستجوى مكرر درمان بزشكى بيش بينى كند(1) (1). شديدترين

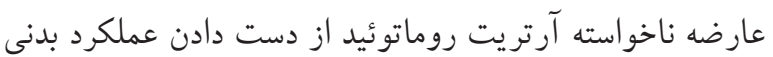

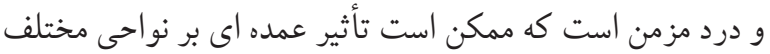

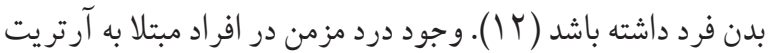

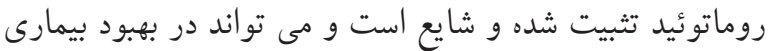
تاثير بكذارد (I (I). يكى از مسائلى كه در حوزه رفتارشناسى بيماران، شناخت اندكى درباره آن وجود دارد اين است كه جرا افر ادى كه در معرض عو موامل استرس زاى مشابه قرار مى گيرند و ويز گیىهاى بالينى مشابه دارند به شيوههاى مختلف علايم بيمارى را ادراك و تفسير مى كنند و رفتارهاى مبتنى بر بيمارى متفاوتى نشان مىدهند. اعتقاد بر اين

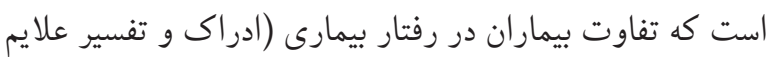

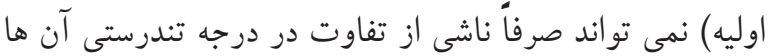
باشد. علايمى كه ممكن است از سوى يك خانواده يا يك فرد، نابهنجار تفسير شده باشد، و در نتيجه به ملاقات مكرر بيمار با يزشك منجر كردد احتمالا توسط فرد يا خانواده ديكر كم اهميت

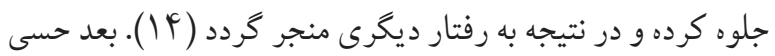

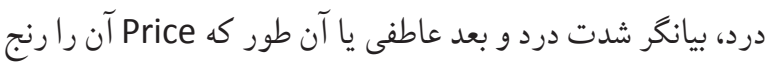
درازمدت ناميده، نشان دهنده ى ميزان ناخشنودى و ادر اكات فرد

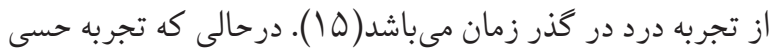

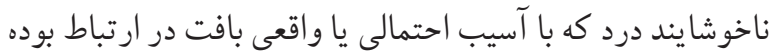

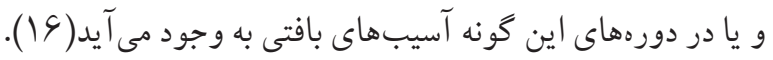

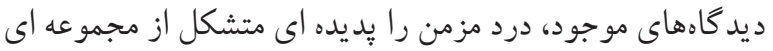

درد پِديده اي فراگير است كه تقريبا همه افراد درطول عمر خود آن را به نوعى تجربه مى كنند. شايد درد عمومى ترين فشار روانى باشد

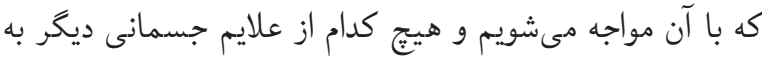
فراكيرى درد نيستند ( (). طبق تعريف انجمن بين المللى مطالعه IASP-International Association for the Study of (درد Pain

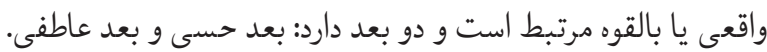

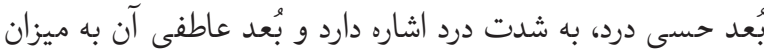
ناخشنودىاى كه فرد تجربه مى كند، اطلاق مىشود (Y). همجنين، از نظر طول مدت درد به دو دسته تقسيم مىشود؛ درد حاد و درد مزمن. درد حاد دردى است با علت كاملا معين و دوره مشخص. در مقابل درد مزمن، به عنوان درد مداوم يا مكرر تعريف شده است كه به مدت ץ ماه يا بيشتر ادامه دارد (ץ). تشخيص كذارى بيمارى مزمن بر بيمار باعث ايجاد رنج قابل ملاحظه اى هيجانى و جسمانى

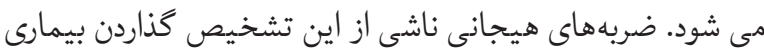

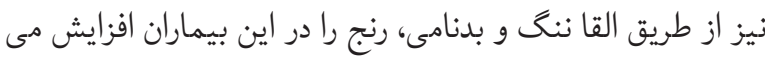
دهد. رنج ايجاد شده به وسيله بيمارى مزمن، فراسوى تجربه و ادراك

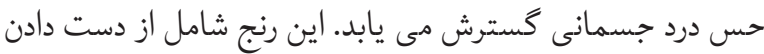

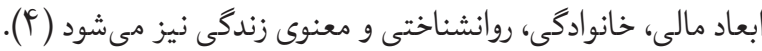

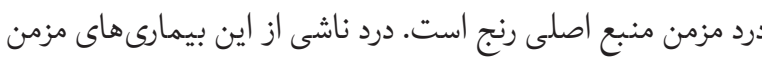
در عملكرد روزانه، تداخل ايجاد مىنمايد و اغلب با بريشانى همراه است. با اين حال، در طبقه بندى بين المللى بيمارى ها، تشخيص درد مزمن به طور سيستماتيك نشان داده نمى شود (ه).

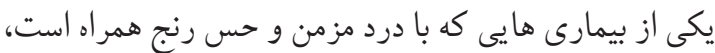
آرتريت روماتوئيد (التهاب روماتيسمى مفاصل) Rheumatoid (Arthritis (RA التهابى و خود كار نظام ايمنى با دركيرى جند نظام بدن مى باشد كه

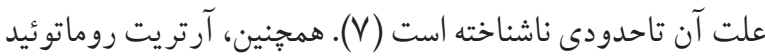
شايع ترين بيمارى روماتيسم خود ايمنى سيستماتيك است (^).

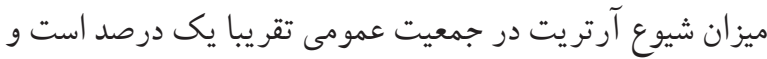


مختلف با هر نوع مهارتى كه داشته باشند، وظايف خود را به نحو

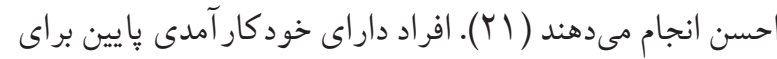

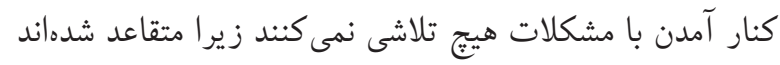

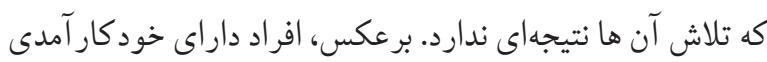

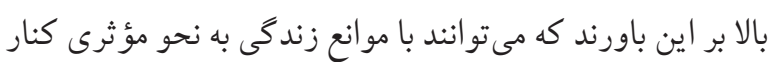

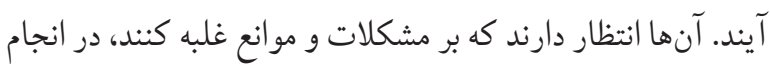
كارها استقامت مى كنند، اغلب عملكرد سطح بالايى دارند و كمتر

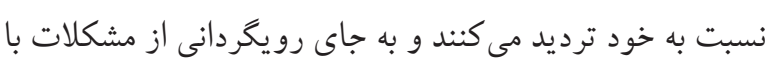

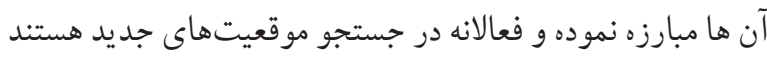

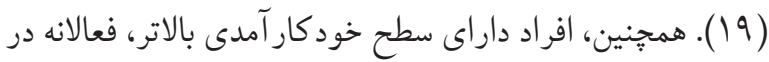
برنامه مراقبت از خود شركت مى كنند و در كنترل بيمارى خود

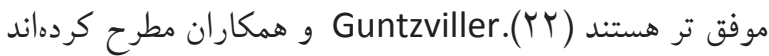

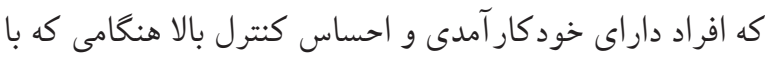

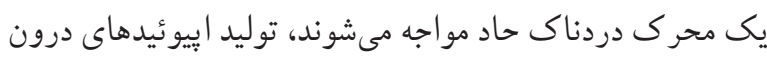
زاد در آن ها افزايش مى يابد كه اين امر باعث افزايش حس كن منترل

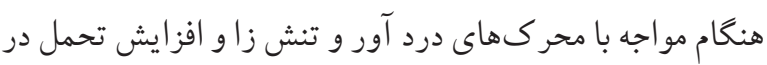

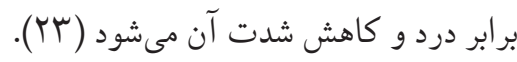

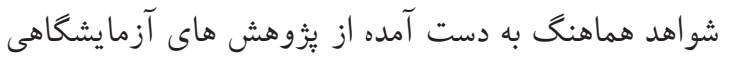
و بالينى نشان مىدهد كه احساس خود كار آمدى در بيماران مبتلا

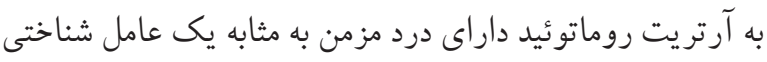

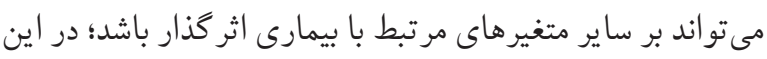

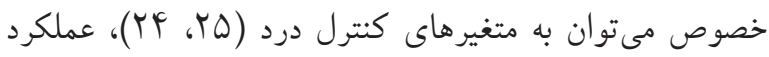

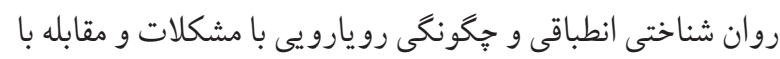

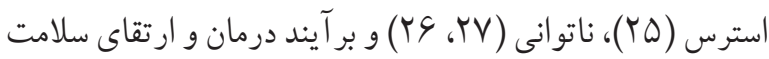

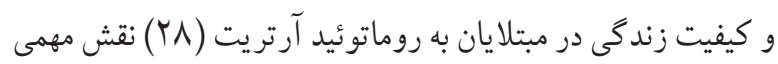

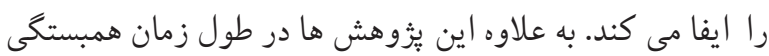

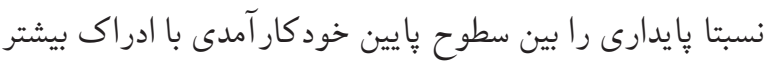

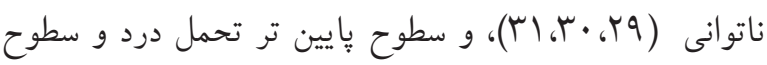
بالاتر شدت درد گز ارش شده را نشان مى دهند (Trا). يافته هاى

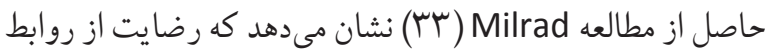
و خود كار آمدى بيماران مىتواند خستكى ناشى از درد مزمن را رال
از علائم زيستى - روانى و اجتماعى مى داند و معتقد است به موازات

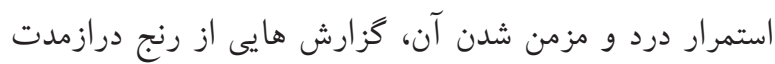

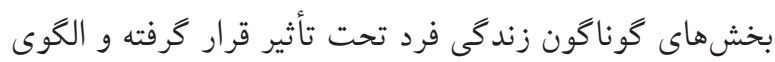

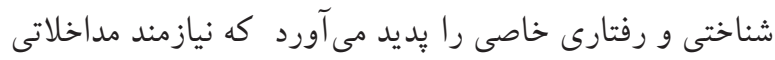

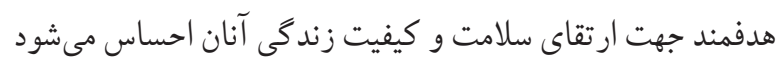

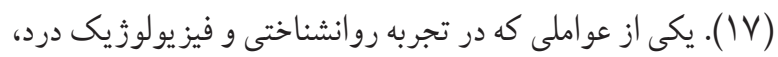
نقش واسطه اى قدر تمندى ايفا مى كند، احساس خود كار آمدى است.

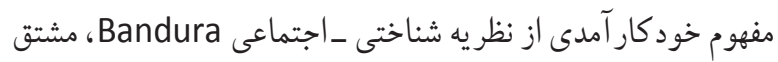

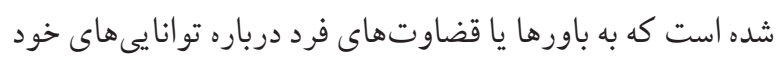

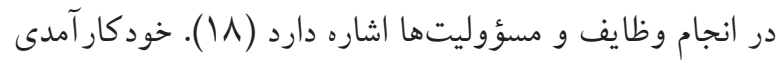
باور يا اعتقادى است كه يك شخص به قابليتها يش در انجام دادن يك رفتار ويثه و يا در ايجاد ييامد مورد نظر دارد (19) بندورا

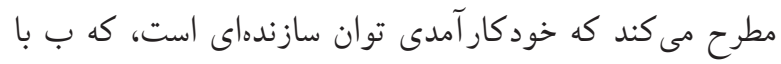
واسطه آن مهارتهاى شناختى، اجتماعى، عاطفى و رفتارى انسان براى تحقق اهداف مختلف، به كونهاى اثربخش ساماندهى مى شوندا

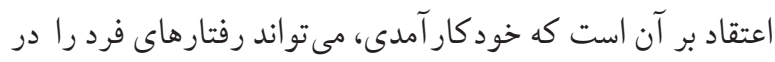
جهت مديريت شرايط ايجاد شده مزمن و نيل به اهداف بهداشتى

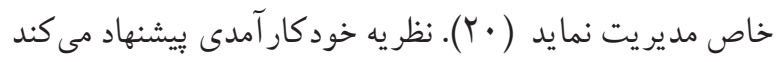

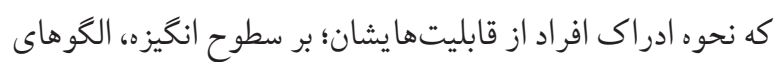
فكرى، واكنشهاى هيجانى، رفتارى و مقدار استرسى كه تجربه

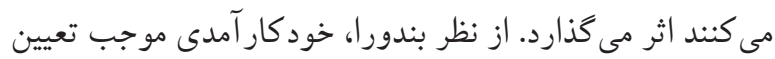

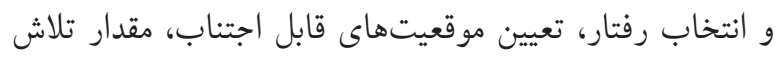

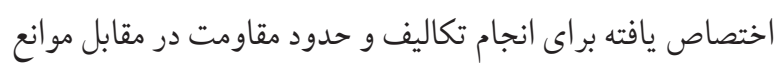
مىشود. به نظر وى داشتن دانش، مهارتو دستاوردهاى قبلى افراد

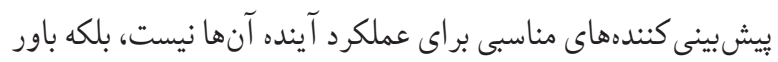

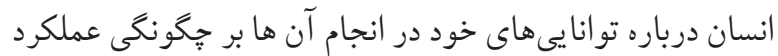

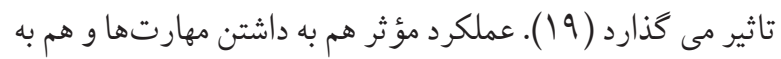

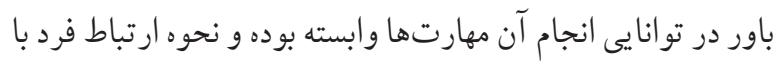
محيط تاحدودى تحت تاثير قضاوتهاى فرد در مورد تو انايىهاى خود است. بدين معنى كه افرادى كه باور داشته باشند مى توانند

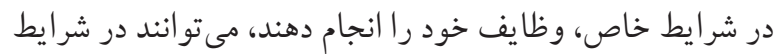


مواد و روش ها

يُزوهش حاضر يك مطالعه توصيفى و از نوع همبستخى و كه مبتنى بر مدل يابى معادلات ساختارى انجام شد. جامعه آمارى ئرى

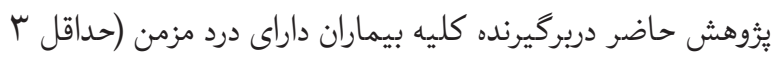

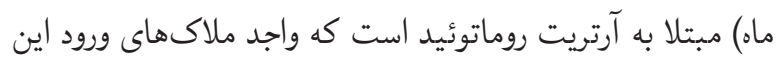

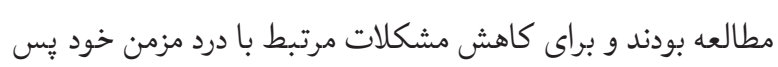
تشخيص توسط متخصص روماتولوزى به جند الدرمانگاه و مركز

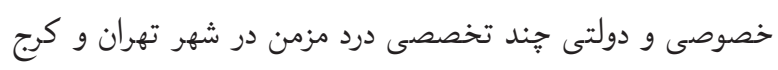

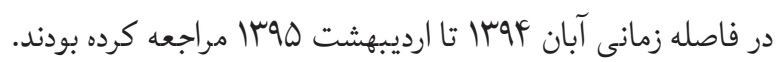

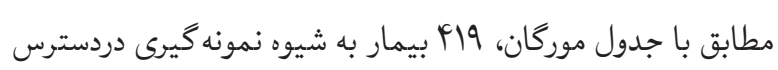

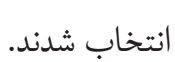

به منظور جمع آورى داده ها از سه برسشنامه به شرح ذيل استفاده شد:

ا - سياهل خلاصه شده و تجديد نظرشده درد مك گيل Short (form of McGill Pain Questionnaire (SF-MPQ درد مك كيل از برجسته ترين ابزار اندازهيرى درد (به ويثه درد

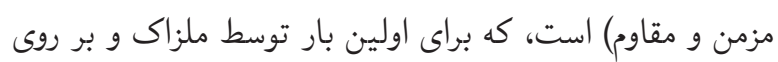

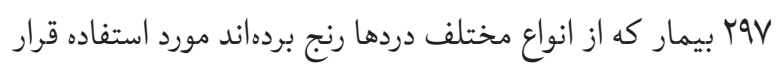

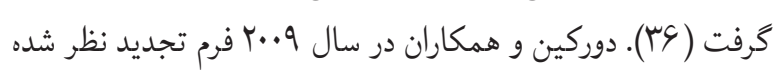

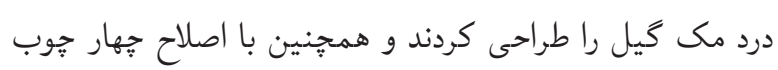

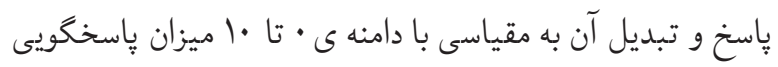

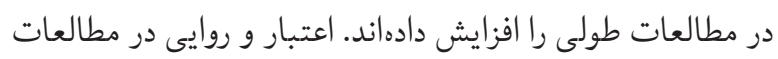

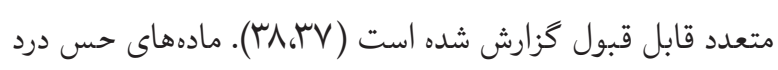

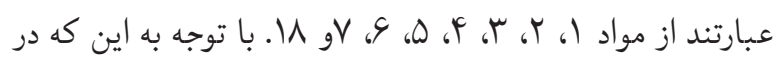

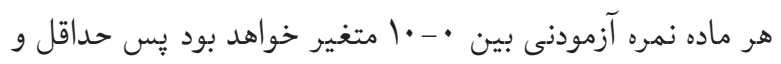
حداكثر نمرات اكتسابى در حس درد •-. •^ خواهد بود؛ كه نمره

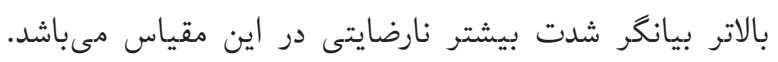

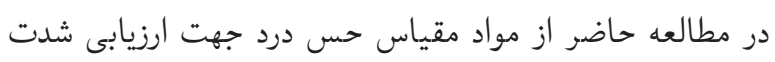

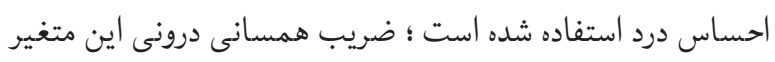
در مطالعه حاضر شه/ كزارش شده است.
كاهش دهد. براين اساس بيماران درد مزمن ممكن است به علت

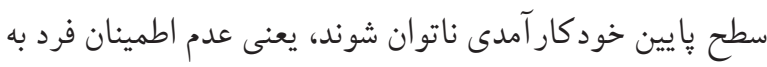

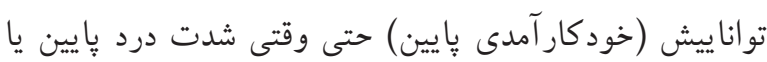

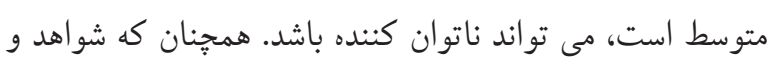

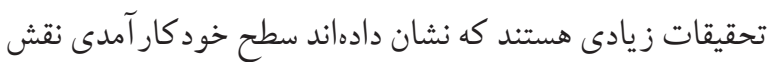

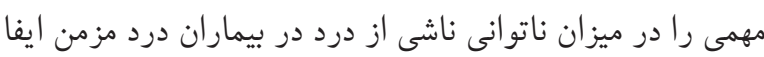

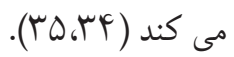
بنابراين از يك طرف با توجه به اثرات خود كار آمدى كه به عنوان

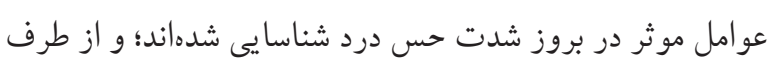

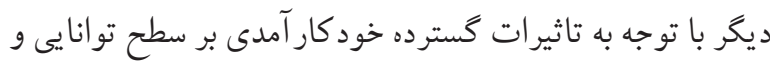
انطباق روانشناختى بيمار، مى توان خود كار آمدى در رابطه با درد را

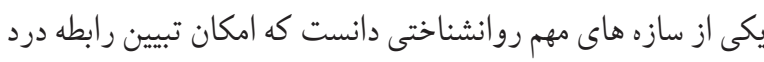
مزمن و رفتارهاى مر تبط با درد را فر اهم مى كند. اهميت درده، مفهوم

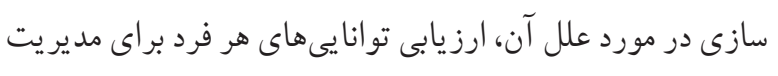
درد، تحميل هزينههاى مادى و معنوى بر فرد، خانواده و جامعه، لزوم تدوين مدلهاى تبيين كننده درد جهت استفاده در مداخلات

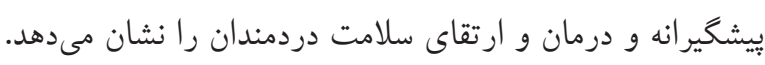

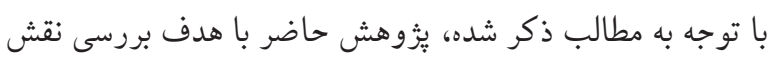

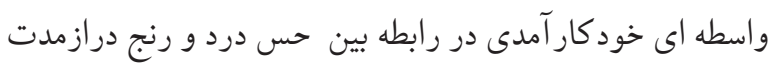

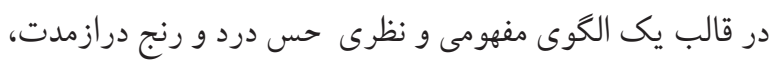

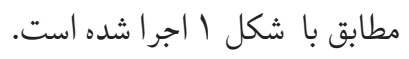

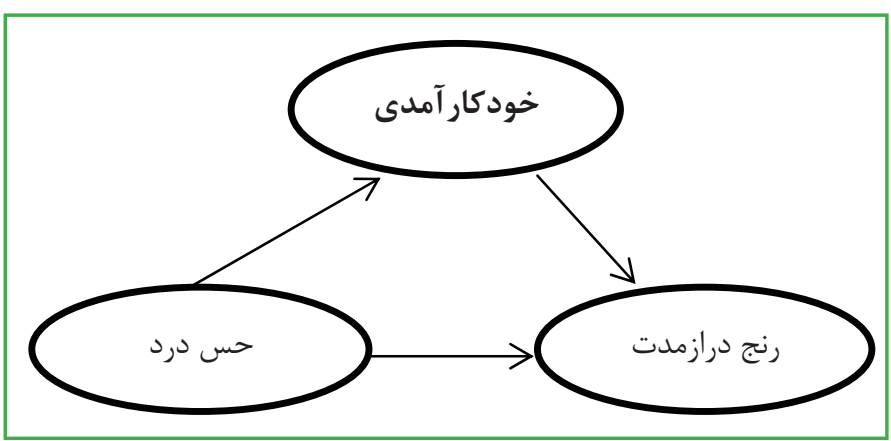

شكل ا. مدل مفهومى نقش واسطه اى خودكار آمدى در رابطه بين حس درد و رنج درازمدت (جهت ساده سازى نشانگر ها حذف مدف

شدهاند) 


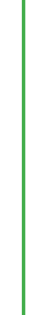

شدند. به منظور جلب همكارى بيماران بر حفظ محرمانه بودن اطلاعات و بى نام بودن برسشنامهاى هآ آنان تاكيد شد.

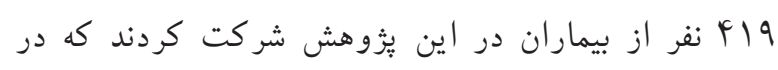

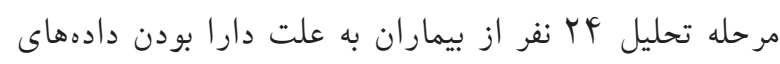

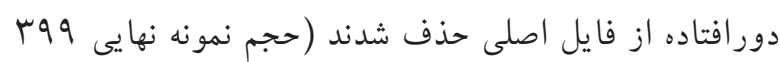

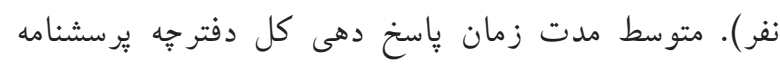
حدود • ب دقيقه بوده است. به منظور عدم تاثير كذارى ترتيب

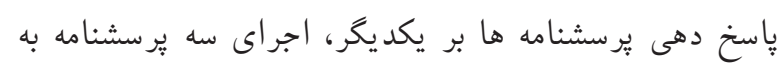
كونه تصادفى تدبير شده بود.

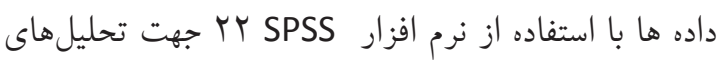

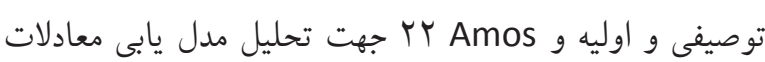
ساختارى SEM مورد بررسى قرار كرفتند.

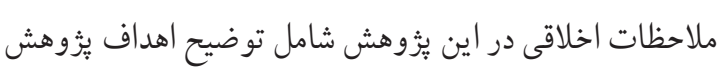
براى هر يك از آزمودنى ها در مطالعه و كسب رضايت آكاهانه

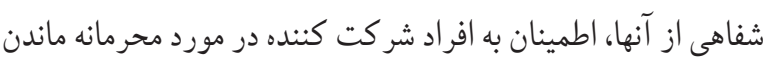

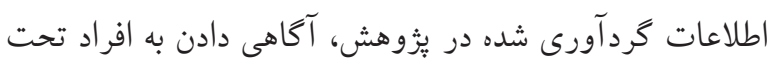

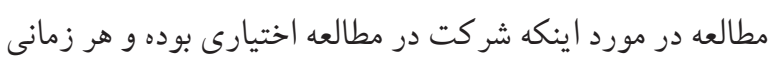

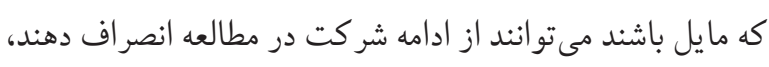

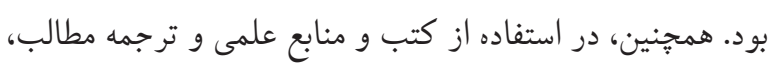
رعايت حقوق ادبى و امانت به عمل آمد.

يافتنه ها

يافته هاى توصيفى نشان مىدهد كه از 99 نفر آزمودنى كه اطلاعات

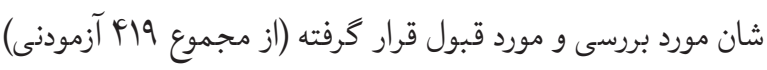

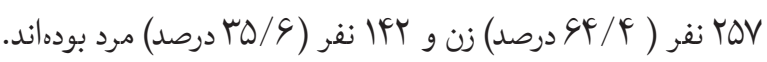

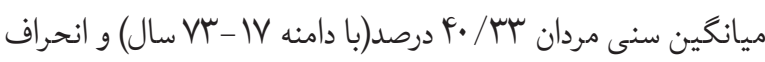

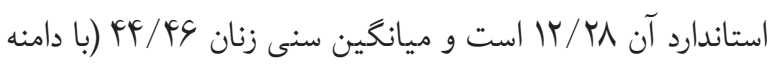

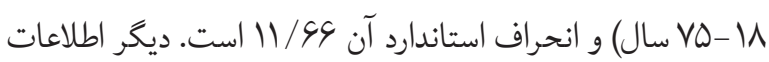
جمعيت شناختى در جدول ال ارائه شده است.
Y-بقياس احساس ناراحتى درد Pain Discomfort Scale:

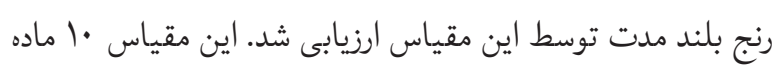

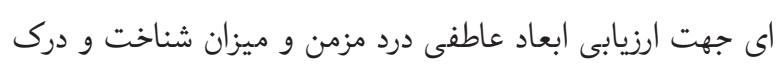

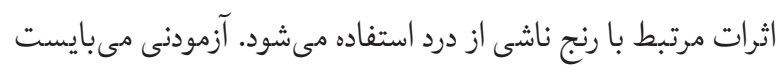

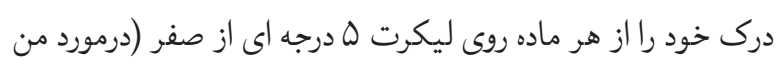

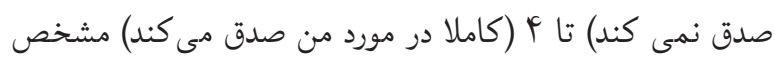
نمايد. جنسن ( و (T) همسانى درونى اين آزمون و آلفاى كورنباخ

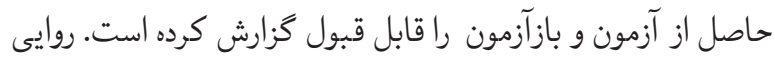
اين آزمون نيز درمقايسه با ساير ابزارها مورد تاييد قرار گرفته است.

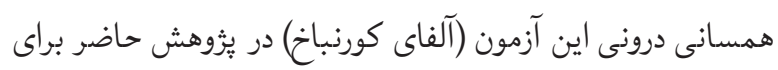
كل مقياس VY • • محاسبه شده است.

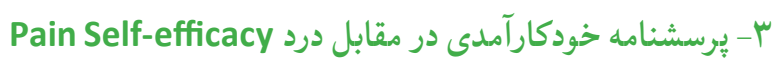
Questionnaire (PSEQ

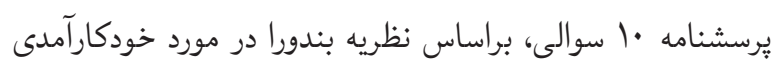
ساخته شده است و به منظور ارزيابى باور بيمار از تواناييش در انجام فعاليتهاى گوناگون على رغم وجود درد توسط Nicolas (1919 )

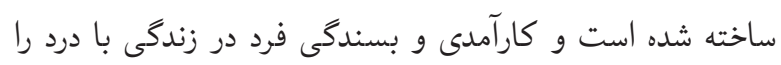

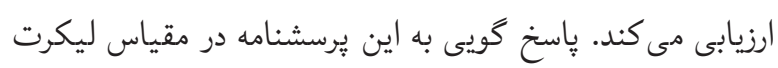

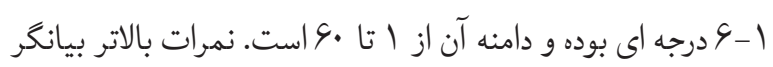

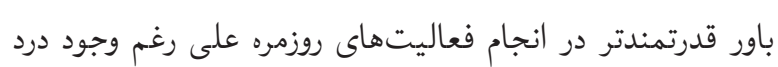
است (צץ). براى بررسى اعتبار برسشنامه، اصغرى مقدم و همكاران

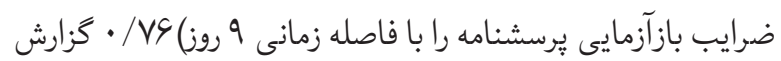

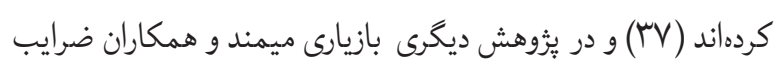

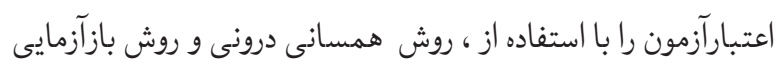

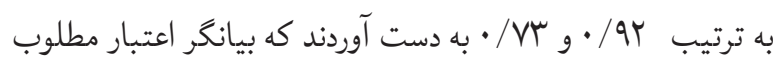

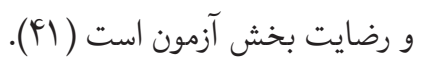

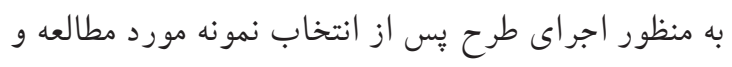

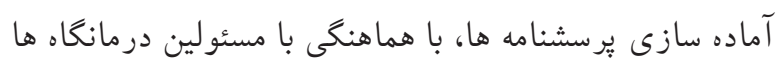

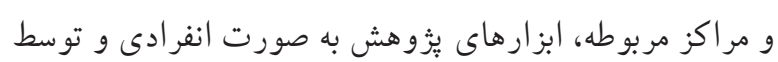

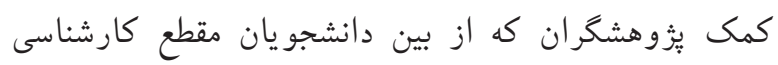
انتخاب شده بودند و از اهداف يُزوهش مطلع نبودند؛ تكميل 
همان طور كه در جدول ץ نشان داده شده است مقادير شاخصهاى

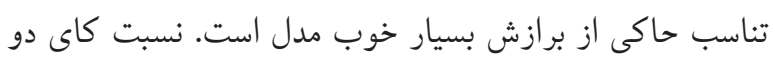

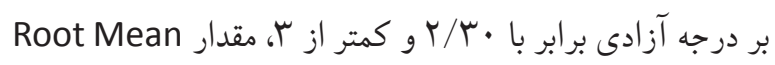
Squares Error Approximation (RMSEA)

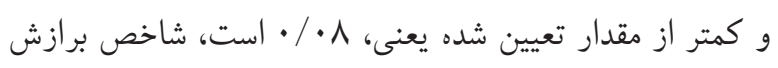

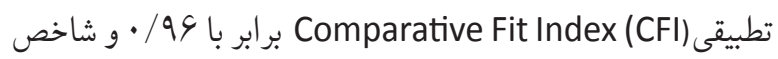

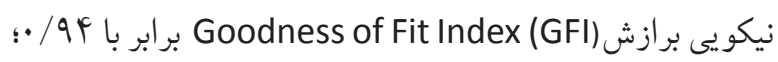
هر دو بالاتر از مقدار مجاز يعنى •9/ • • است. ضرايب مسير و ميزان معنادارى مربوط به هر مسير در جدول بار ارائه شده است.

جدول س. ضرايب مستقيم حس درد و صفت خشم بر رنج درازمدت

\begin{tabular}{|c|c|c|c|c|}
\hline نتيجه & ارزش t & ضريب مسير & \multicolumn{2}{|c|}{ مسير } \\
\hline تاييد مدل & S/G^. & 米·|q1 & خود كار آمدى & حس درد \\
\hline تاييد مدل & $\vee / 9 \wedge 0$ & * $\cdot / \Delta \Delta$ & رنج درازمدت & حس درد \\
\hline تاييد مدل & $r / s \Delta r$ & 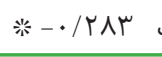 & رنج درازمدت & خود كار آمدى \\
\hline$d f=\Delta 1$ & \multicolumn{2}{|c|}{$\begin{aligned} \text { RMSEA } & =\cdot / \cdot \Delta \\
d f / X^{r} & =r / \mu . \quad X\end{aligned}$} & $\begin{array}{l}=\cdot / 99 \quad G F \\
=11 \mathrm{~V} / \mathrm{Kr}\end{array}$ & $\mathrm{GFI}=\cdot / 9 F$ \\
\hline \multicolumn{5}{|c|}{$\mathrm{p}<\cdot / \cdot \Delta$} \\
\hline
\end{tabular}

همان طور كه در شكل Y مشاهده مى شود هر دو متغير حس درد

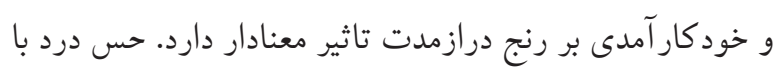

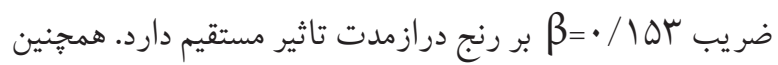

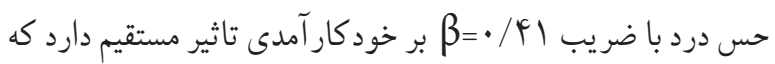

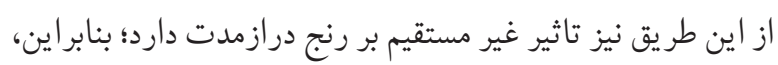

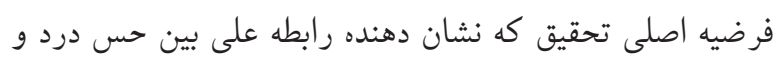
رنج درازمدت به واسطه خودكار آمدى بود تاييد شد. نهايتا نتايج

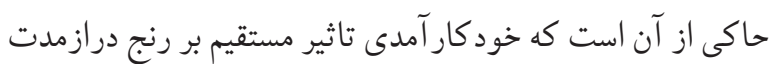

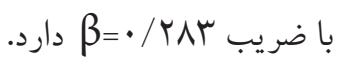
ارزيابى روابط غيرمستقيم با استفاده از روش بوت استر بِ نش نشان

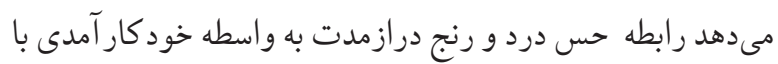

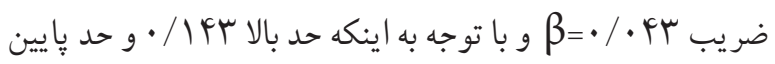

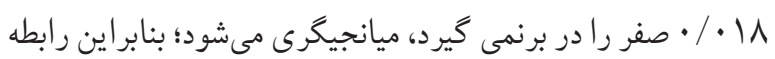

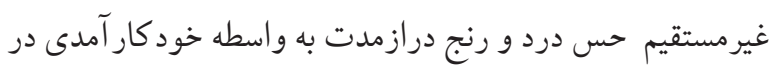
سطح rr • • معنادار است.
جدول ا. ويثز گهاى جمعيت شناختى - فراوانى

\begin{tabular}{|c|c|c|c|}
\hline زنان & مردان & & \\
\hline 19. & VS & \multirow{2}{*}{ ديڤلم و يايين تر } & \multirow{12}{*}{ ميزان تحصيلات } \\
\hline$\% S Y / \Delta$ & $\% \Delta F / \Delta$ & & \\
\hline pr & rq & \multirow{2}{*}{ فوق دييلم } & \\
\hline$\% 19$ & $\% r \cdot / r$ & & \\
\hline$r q$ & $r \Delta$ & \multirow{2}{*}{ كارشناسى } & \\
\hline$\% 11 / 1$ & $\% 1 V / s$ & & \\
\hline 1. & r & \multirow{2}{*}{ كارشناسى ارشد } & \\
\hline$\%$ \%/ᄉ & $\%$ \%/入 & & \\
\hline r & 1 & \multirow{2}{*}{ د دكترى } & \\
\hline$\% \cdot / \Lambda$ & $\% \cdot / V$ & & \\
\hline If & $\checkmark$ & \multirow{2}{*}{ نامشخص } & \\
\hline$\% \Delta / \mu$ & $\% 4 / 9$ & & \\
\hline id & $\Delta \Delta$ & \multirow{2}{*}{ مجرد } & \multirow{8}{*}{ 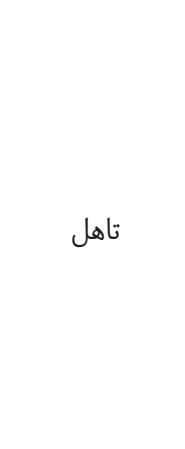 } \\
\hline$\% 1 V / r$ & $\%$ \% & & \\
\hline 199 & $\wedge$. & \multirow{2}{*}{ متاهل } & \\
\hline$\% \vee s / r$ & $\% \Delta s / r$ & & \\
\hline 1. & r & \multirow{2}{*}{ فوت يا جدا شده } & \\
\hline$\% \mu / \Lambda$ & $\% r / \Lambda$ & & \\
\hline s & r & \multirow{2}{*}{ نامشخص } & \\
\hline$\% \Gamma / \mu$ & $\% r / 1$ & & \\
\hline
\end{tabular}

مطابق جدول Y همبستكى بين متغيرهاى ثيزوهش مثبت و روابط

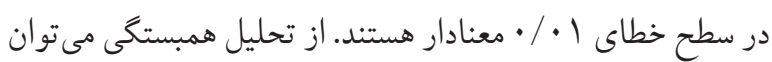

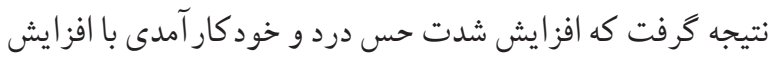
احساس رنج درازمدت همراه است. به منظور ارزيابى رابطه بين حس درد و رنج درازمدت به شكل مستقيم و همجنين بررسى رابطه

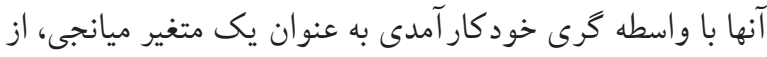
روش مدل يابى معادلات ساختارى استفاده شده است (جدول با ب). جدول rا. ماتريس همبستغى بين متغير هاى ثئوهش

\begin{tabular}{|c|c|c|c|}
\hline \multicolumn{4}{|c|}{ ا.درد حسى r.خود كارآمدى ب.رنج درازمدت } \\
\hline & & 1 & 1.درد حسى \\
\hline & 1 & 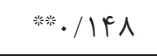 & r.خود كار آمدى \\
\hline 1 & 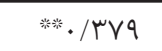 & 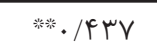 & س.رنج درازمدت \\
\hline
\end{tabular}




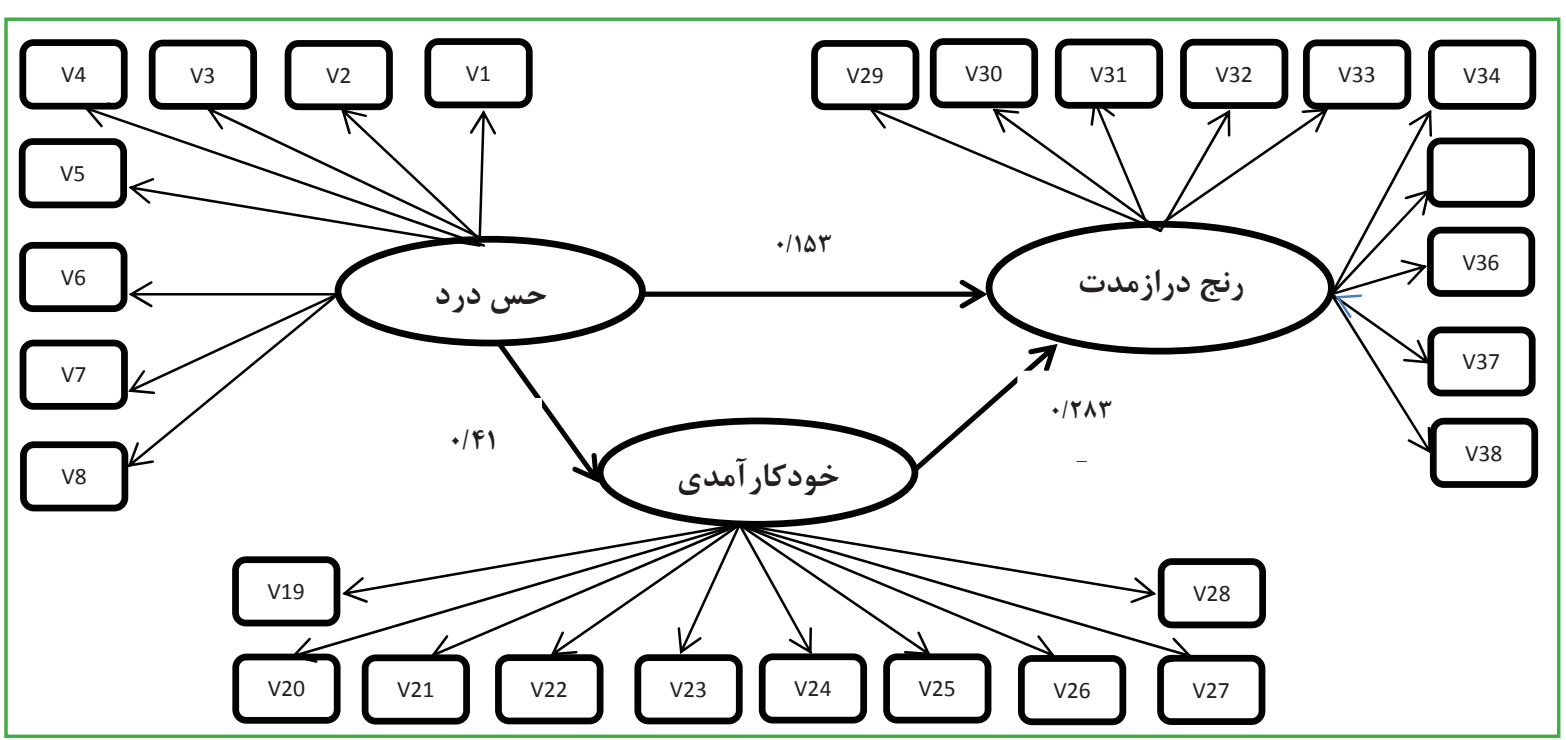

شكل r. ساختار نهايى روابط مستقيم و غير مستقيم متغير هاى حس درد و رنج درازمدت و خودكار آمدى( ضرايب نشانگر ها و ضرايب خطا جهت ساده تر شدن از مدل حذف شدهاند

عبارت ديكر نتايج ارزيابى مدل ساختارى نشان داد كه بين حس

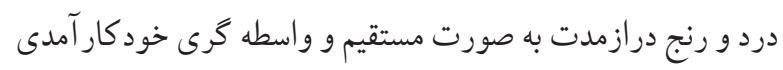

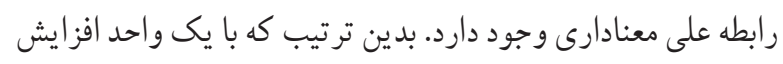

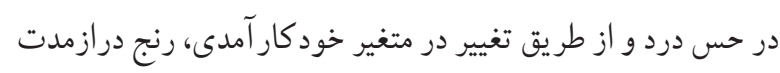

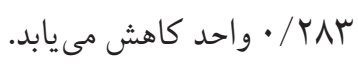
اين يافته ها، با مطالعاتى كه در زمينه نقش خودابد كاردار آمدى بر

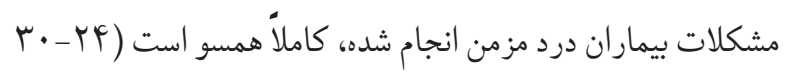

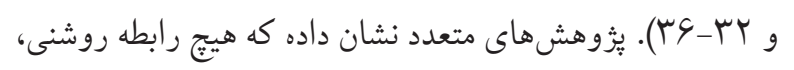

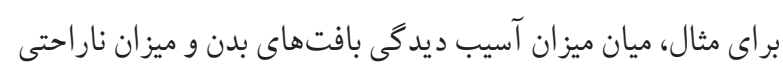

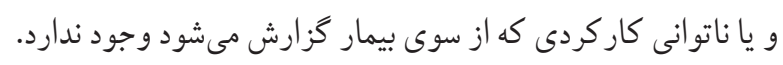

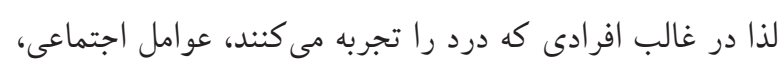

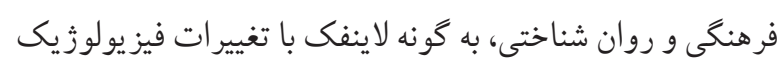

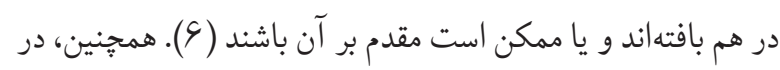

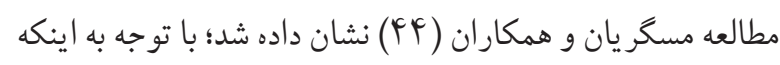
درد شديد، احساس خود كار آمدى ضعيف و افكار فاجعه آفرين زياد،

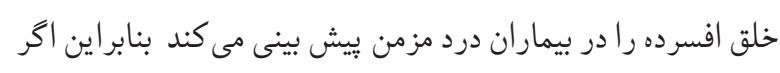

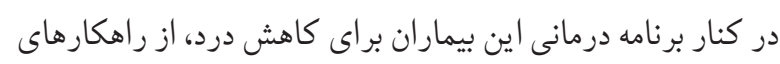

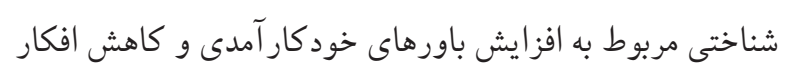

درد بديده ایى است كه توسط هر فرد در طول زندگى تجربه مىشودو

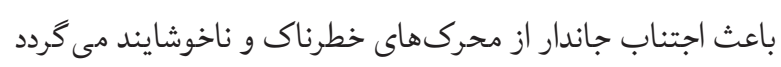
و از اين طريق در حفظ حيات او نقش مهمى دارد. اخرجه وجود درد

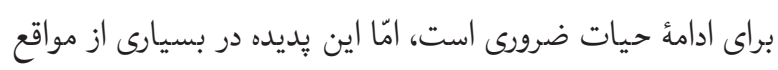

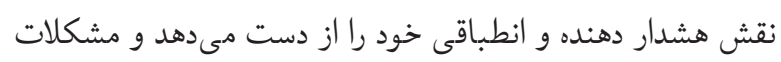

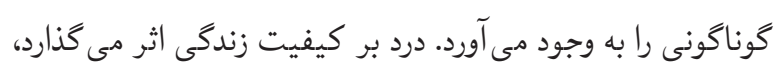

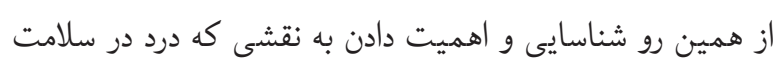

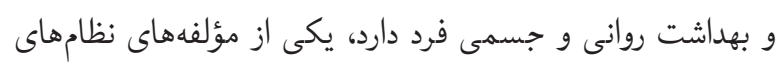

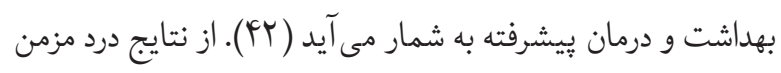
رنج درازمدت است. حس رنجى كه بيماران مبتلا به درد مزمن

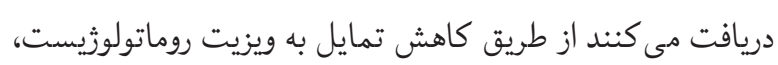

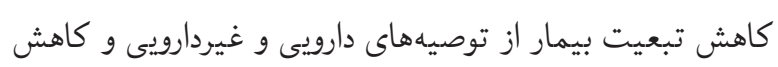

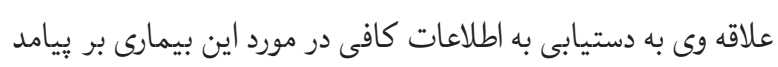

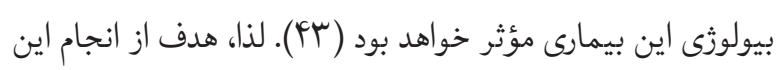

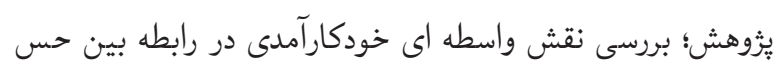
درد و رنج دراز مدت بود. در اين راستا، يافتهاى يُزوهش نشان داد خود كار آمدى مى تواند

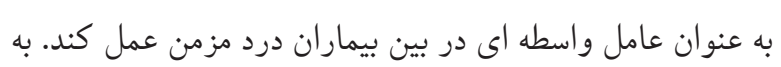


باورهاى خودكار آمدى آثار مختلفى رادر طى جهار فر آيند عمده

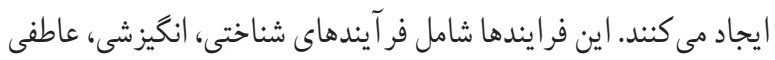

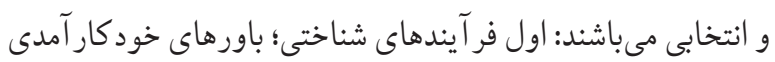
بر الكوهاى فكرى كه ممكن است خود كمك كننده يا خود تخريب

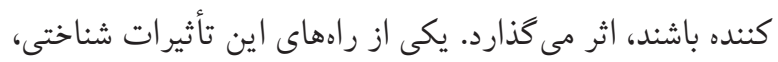

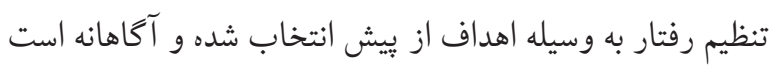
و تعيين اين هدف شخص، تحت نفوذ خودارزيابىها و ظرفيتهاى

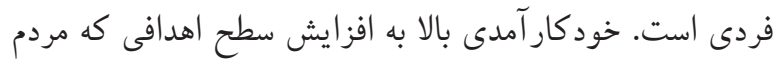

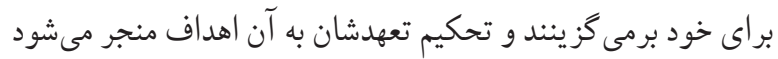

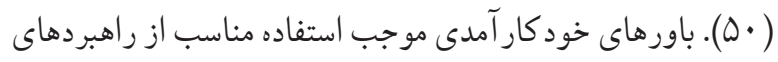

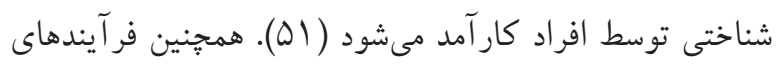

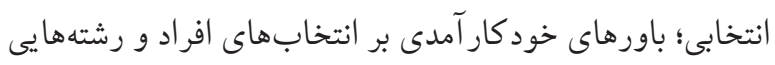

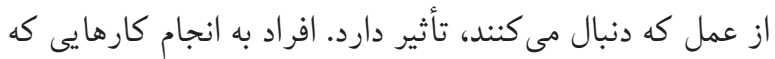

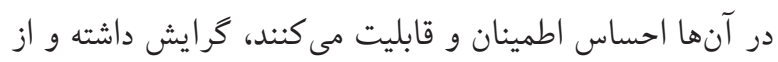
كارهايى كه در آنها احساس قابليت و اطمينان نمى كنند، دورى إنى

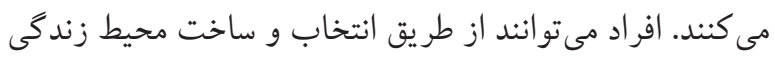
خود تا حدى بر جريان زندگى خود اثر بكذارند. افراد تمايل دارند تا از فعاليتدر موقعيت هايى كه باور دارند بيشتر از حد تو توانايى نداني آنها است اجتناب كنند و فعاليتهايى در محيط اجتماعى انتخاب لئي

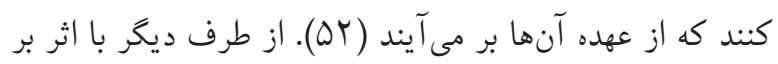
فر آيندهاى عاطفى؛ در نظم بخشيدن به موقعيتهاى هيجانى نيز

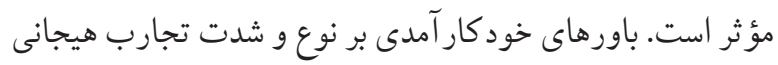

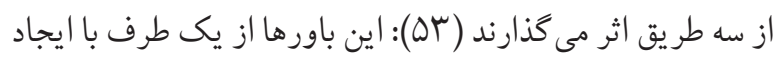

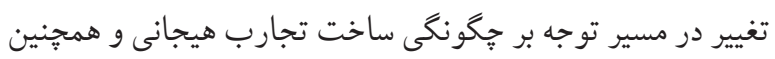

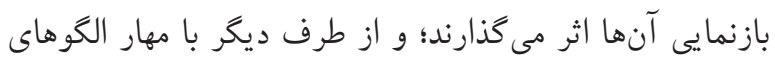

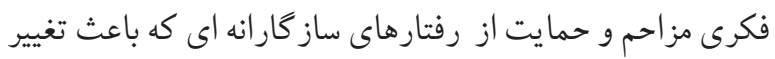
محيط مىشوند؛ موجب تعديل توان بالقوه هيجانى بيمار در برخورد

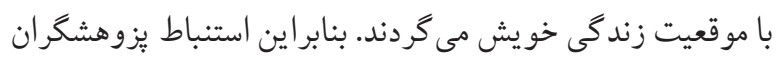

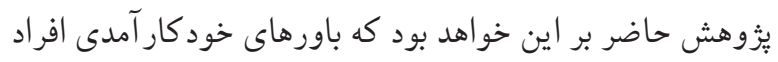

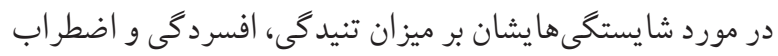
در موقعيتهاى تهديدآميز تأثير مى گذارد. هنگامى كه افراد باور

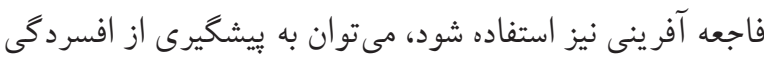

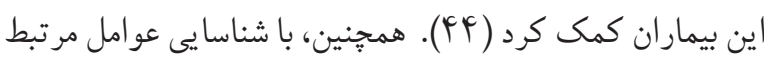

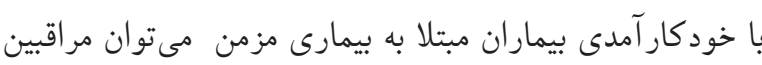

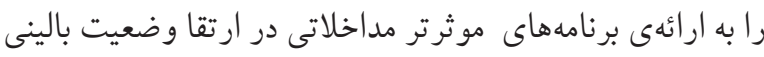

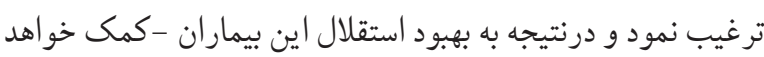

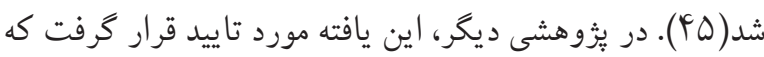

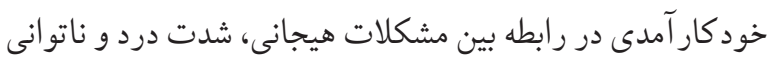

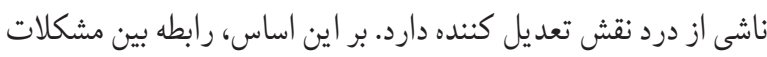

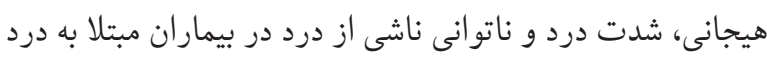

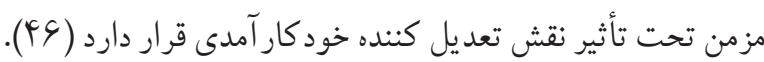

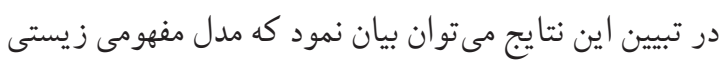

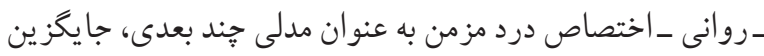

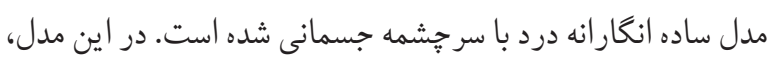
عوامل روان شناختى و اجتماعى به عنوان عو املى تلقى مى كه به طور غير مستقيم با فرايند ادراك درد رابطه دارند. به مرور

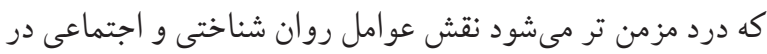

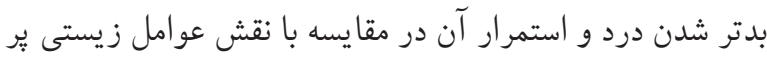

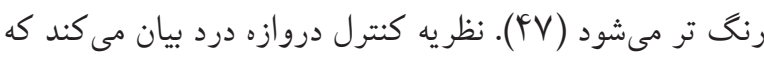
نوعى مكانيزم دروازه اي در نخاع شوكى، نقش ميانجى را در تكانه

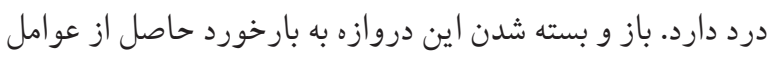

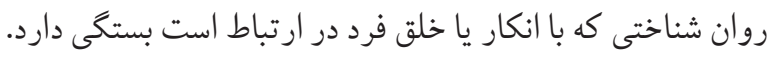

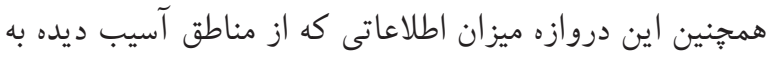

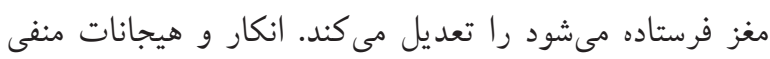
دروازه را باز مى كند كه باعث مى مود اطلاعات بيشترى درباره

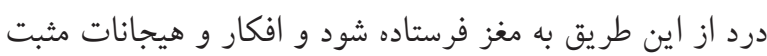

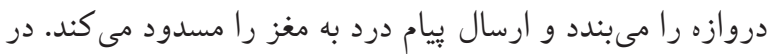

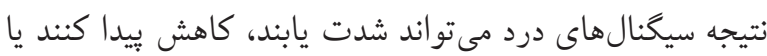

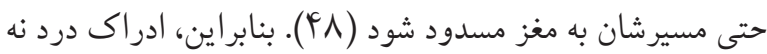

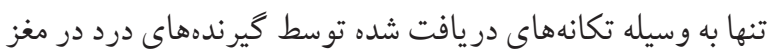

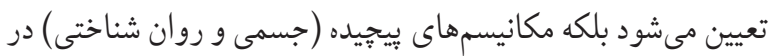
سطوح مختلف نخاعى و قشرى مى تو انند آن را تعديل كنند (19). 
و نيز دستكاه مر كزى تعديل كنده درد، شدت درد را افزايش دهد. رابطه عميقى بين هيجان و درد مزمن وجود دارد ـ هيجان ها زمينه

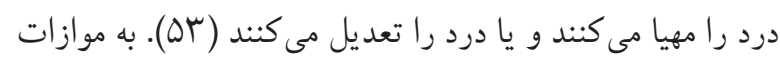

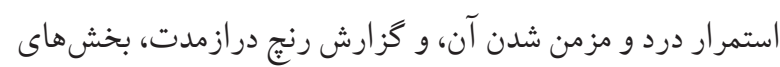
كوناخون بيمار مبتلا به آرتريت روماتوئيد تحت تاثير قرار مئ كيرد. به نظر مىرسد الخوى جديد شناختى كه فرد تجربه مى كند به تغيير

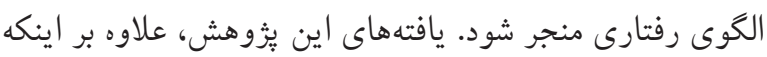

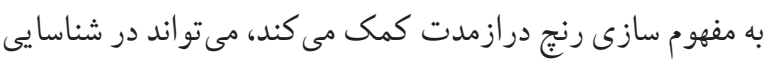
عوامل شناختى رنج درازمدت، ارائه راهبردهاى انطباقى تر افراد

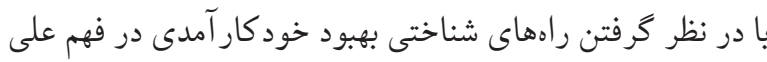

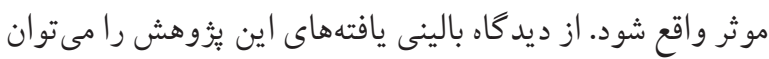

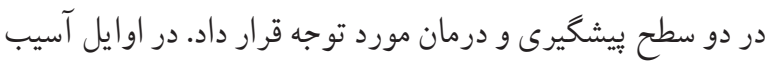

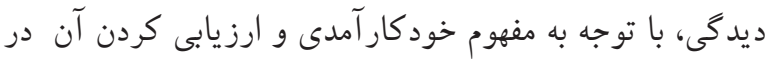

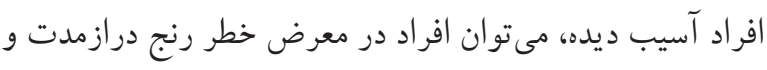

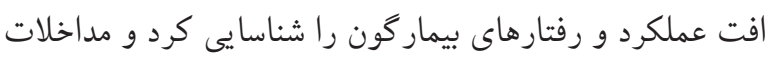

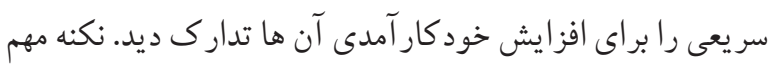
شناسايى به موقع افراد در معرض خطر است. مراكز مرتبط، با تدوين

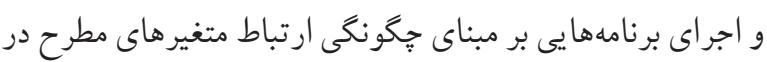

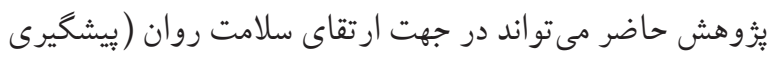

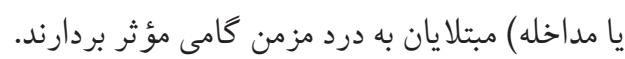

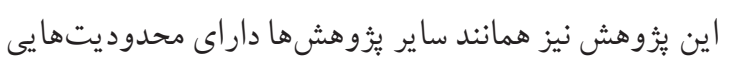

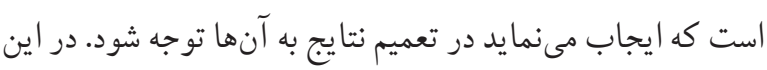

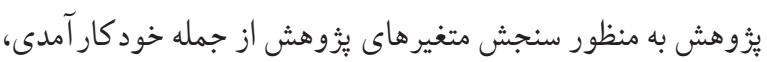

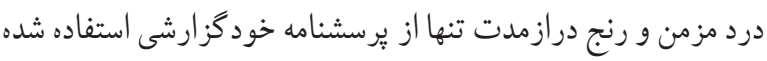
كه ممكن است در نتايج به دست آمده مشكل ايجاد نمايد. همجنين

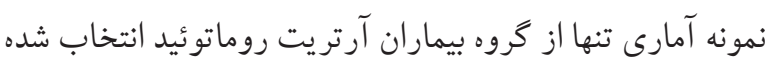

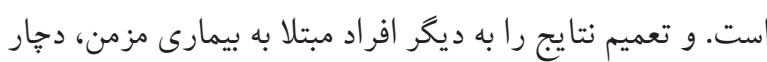

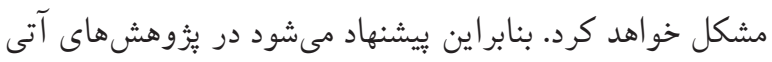

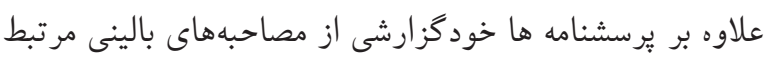

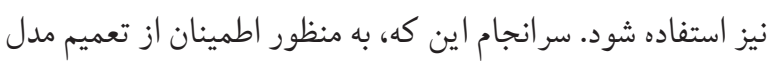
به ساير جمعيتهاى بالينى با ساير اختلالات نظير فيبروميالزى و
دارند مى تواند تهديدها يا فشار محيطى را مهار كنند، الكوهاى

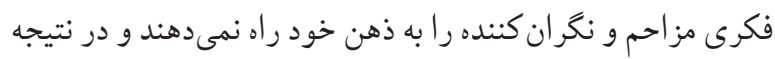

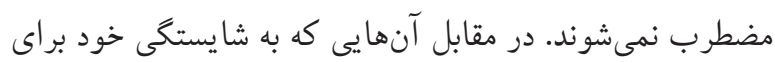

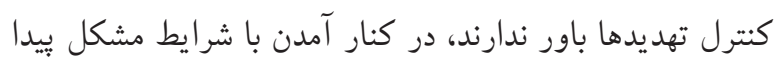

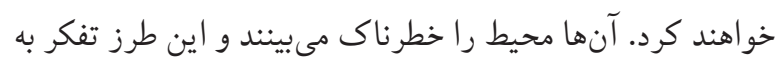
عملكرد آن ها آسيب مىزند و در نتيجه فرايندهاى انكيزشى نيط نيز

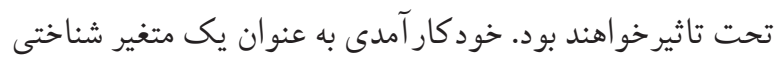

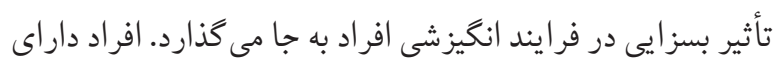

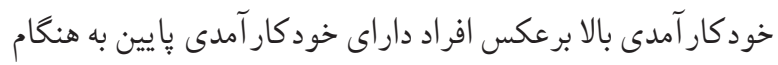

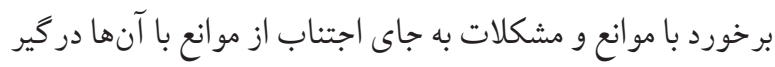
مىشوند و پايدارى و استقامت بيشترى از خود نشان مىدهند

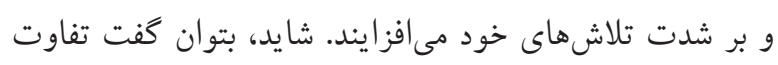

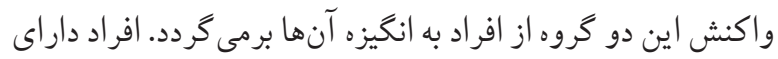

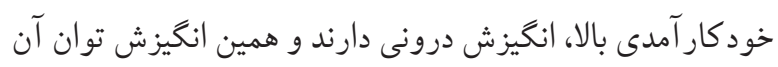
ها را براى برخورد با موانع بسيج مى سازد.

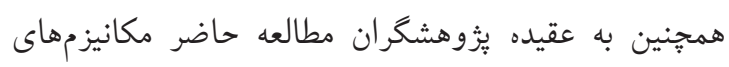

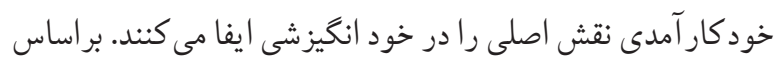

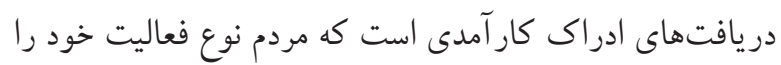

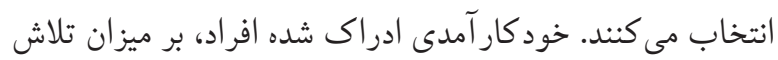

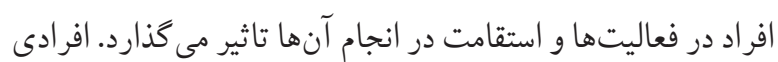

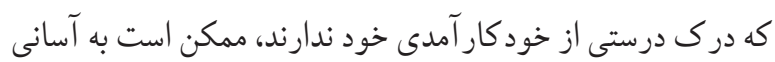

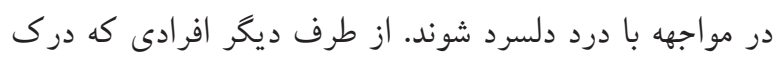

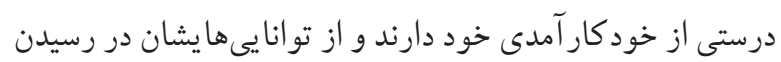

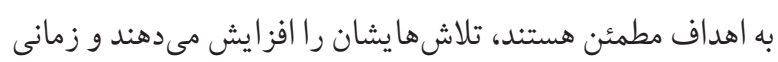
كه عملكر دشان رضايتبخش نباشد، به تلاش خود ادامه مىدهند تا

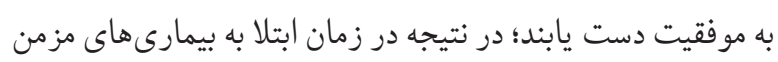
نظير آرتريت روماتوئيد، رنج كمترى را كزارش خواهند كرد.

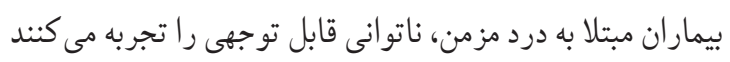

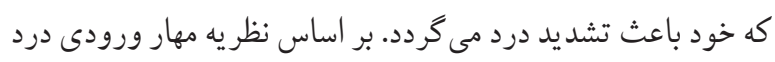

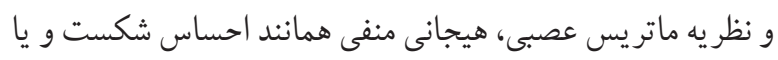

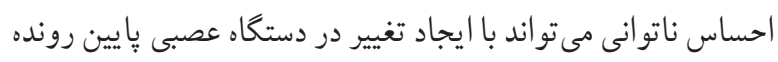


دكترى روان شناسى سلامت) با هدف ساخت مدل اير انى از فر آيند

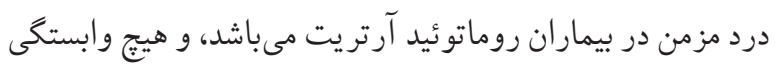
مالى به دستخاه، انجمن و نهاد ديكرى ندارد. تضادمنافع

در اين مقاله هيج گونه تعارض منافع وجود ندارد.

\section{References}

1. Gatchel RJ, Kathryn HR. Evidence-informed management of chronic low back pain with cognitive behavioral therapy. Spine J. 2008; 8: 40-44. [DOI:10.1016/j. spinee.2007.10.007] [PMID] [PMCID]

2. Anbari S, Estaji Z, Rastaqhi S. Assessment effect of rosa damascena juice aromatherapy on elderly chronic musculoskeletal pain in Sabzevar Retirement Clubs. Salmand: Iranian Journal of Ageing. 2018; 13 (2): 250-261 [DOI:10.32598/sija.13.2.250]

3. Aziz Q, Giamberardino MA, Barke A, Korwisi B, et al. The IASP classification of chronic pain for ICD-11: chronic secondary visceral pain. Pain. 2019; 160 (1): 69-76. [DOI:10.1097/j. pain.0000000000001362] [PMID]

4. Pirasteh Motlagh A. A, Nick Manesh Z. Dtermining the relationship between spirituality and suffering and quality of Life in patients. Armaghane danesh Journal. 2012; 17 (70): 337-348.

5. Treede RD, Rief $W$, Barke A, et al. Chronic pain as a symptom or a disease: the IASP Classification of Chronic Pain for the International Classification of Diseases (ICD-11). Pain. 2019.; 160 (1): 19-27. [DOI:10.1097/j. pain.0000000000001384] [PMID]

6. Costello R, David T, Jani M. Impact of adverse events associated with medications in the treatment and prevention of rheumatoid arthritis. Clinical therapeutics. 2019;41(7):1376-96. [DOI:10.1016/j.
[ clinthera.2019.04.030] [PMID]

7. Gibofsky A. Comparative effectiveness of current treatments for rheumatoid arthritis. Am J Manag Care. 2012; 18 (13): 303-314.

8. Ankoor SE. William SC.Rheumatoid Arthritis.Kasper DL, Braunwald E, Fauci A, et al. Harrison's principles of internal medicine.16th Ed, New York: McGraw-Hill; 2005. P. 2738.

9. Davis III JM. Rheumatoid arthritis: a severe disease that preventive approaches would greatly benefit. Clinical therapeutics. 2019;41(7):1240-5. [DOI:10.1016/j.
[ clinthera.2019.04.026] [PMID]

10. Smeltzer S, Bare B, Hinkle J, et al. Brunner and Suddarth's textbook of medical-surgical nursing. 11th revised international Ed. Philadelphia: Lippincott, Williams, Wilkins, \& Wolters Kluwe; 2008.

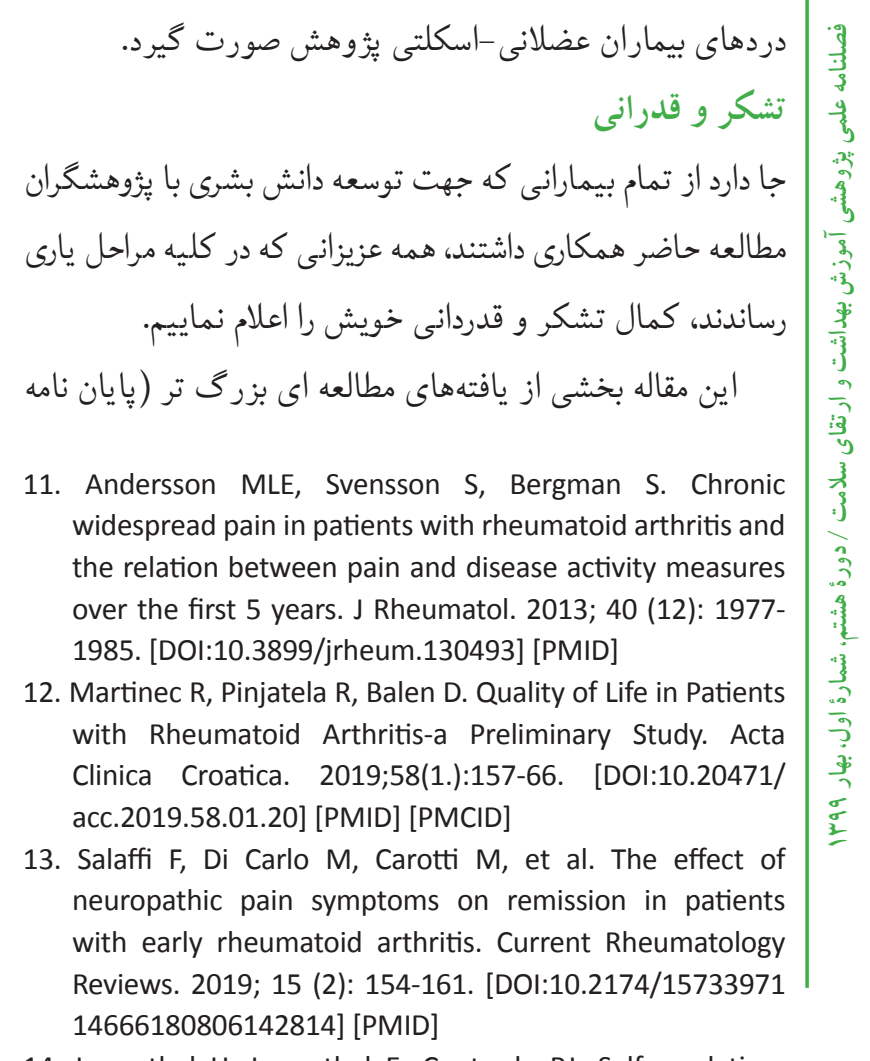

14. Leventhal H, Leventhal E, Contrada RJ. Self-regulation, health \& behaviour: aperceptual cognitive approach. J Health Psychol. 1998; 13: 717-734. [DOI:10.1080/088704 49808407425]

15. Price DD, Verne GN, \& Schwartz JM. (2006). Plasticity in brain processing and modulation of pain. Prog Brain Res, 157, 333-52. [DOI:10.1016/S0079-6123(06)57020-7]

16. Martel ME, Lafontaine MF, Theriault A, Balbinotti $M$. Chronic pain self-efficacy as mediator of the link between romantic attachment insecurity, individual functioning and couple satisfaction: a preliminary study. Revista Praksis. 2016; 2:119-36.

17. Bardeen JR, Fergus TA, Orcutt HK. Experiential avoidance as a moderator of the relationship between anxiety sensitivity and perceived stress. Behav Ther. 2013; 44(3): 459-469. [DOI:10.1016/j.beth.2013.04.001] [PMID]

18. Asghari Moqaddam MA, Rahmati, Shaeyri R. The Mediational Role of Pain Self-Efficacy and Fear of Movement in Explaining the Relationship between Chronic Pain and Disability. Clini Psycholo Stud. 2012; 2(6):141-168.

19. Golkarian P, shafiabady A, Delavar A. Comparison of the Effectiveness of Cognitive Behavior Therapy and Diet Therapy on Weight Reduction and Promotion of Lifestyle Self-Efficacy in Obese People. Iranian Journal of Health Education and Health Promotion. 2018;6(4):340-8. [DOI:10.30699/acadpub.ijhehp.6.4.340] 
20. Bandura A. Self-efficacy: the exercise of control, NY, W.H: Freeman; 1997. P. 94-128.

21. Lael-Monfared E, Tehrani H, Moghaddam ZE, Ferns GA, Tatari M, Jafari A. Health literacy, knowledge and self-care behaviors to take care of diabetic foot in lowincome individuals: Application of extended parallel process model. Diabetes \& Metabolic Syndrome: Clinical Research \& Reviews. 2019;13(2):1535-41. [DOI:10.1016/j. dsx.2019.03.008] [PMID]

22. Alidosti $M$, tavassoli e. Investigating Health literacy, knowledge and self-efficacy in patients with type 2 diabetes referring to health centers in shahrekord. Journal of Health Literacy. 2019;3(4):36-45. [DOI:10.22038/ jhl.2019.38005.1031]

23. Guntzviller LM, King AJ, Jensen JD, Davis LA. Self-efficacy, Heealth literacy, and nutrition and exercise behaviors in a low-income, Hispanic population. Immig minority health. 2017; 19(2):489-93. [DOI:10.1007/s10903-016-0384-4] [PMID]

24. Brown BW, Lorig KR, Sobel DS, et al. Evidence Suggesting That a Chronic Disease Self-Management Program Can Improve Health Status While Reducing Hospitalization: A Randomized Trial. Medic Care. 1999; 37(1): 5-14. [DOI:10.1097/00005650-199901000-00003] [PMID]

25. Lorig K, Chastain RL, Ung E, Shoor S, Holman HR. Development and evaluation of a scale to measure perceived self-efficacy in people with arthritis. Arthritis \& Rheumatism: Official Journal of the American College of Rheumatology. 1989;32(1):37-44. [DOI:10.1002/ anr.1780320107] [PMID]

26. Spinhoven P, Ter Kuile MM, Linssen AC, et al. Pain coping strategies in a Dutch population of chronic low back pain patients. Pain. 1989; 37: 77-83. [DOI:10.1016/03043959(89)90155-3]

27. Bandura A, Locke EA. Negative self-efficacy and goal effects revisited. J Appl Psychol. 2003; 88 (1): 87-99. [DOI:10.1037/0021-9010.88.1.87] [PMID]

28. Dolce JJ, Crocker MF, Moletteire C, et al.Exercise quotas, anticipatory concern and self efficacy expectancy in chonic pain: a preliminary report. Pain. 1996; 24: 365-372. [DOI:10.1016/0304-3959(86)90122-3]

29. O'Leary A, Shoor S, Lorig K, et al. A cognitive-behavioral treatment for rheumatoid arthritis. Health Psychol. 1988; 6: 527-544. [DOI:10.1037/0278-6133.7.6.527]

30. Woby SR, Urmston M, Watson PJ. Self- efficacy mediates the relation between pain-related fear and outcome in chronic low back pain patients. Euro J Pain. 2007; 11 (7): 711-718. [DOI:10.1016/j.ejpain.2006.10.009] [PMID]

31. Nicholas MK. The pain self-efficacy questionnaire: taking pain into account. Eur J Pain. 2007; 11: 153-166. [DOI:10.1016/j.ejpain.2005.12.008] [PMID]

32. Dolce JJ, Crocker MF, Moletteire C, et al. Exercise quotas, anticipatory concern and self efficacy expectancy in chonic pain: A preliminary report. Pain. 1999; 24: 365-372. [DOI:10.1016/0304-3959(86)90122-3]

33. Milrad SF, Hall DL, Jutagir DR, et al. Relationship satisfaction, communication self-efficacy, and chronic fatigue syndrome-related fatigue. Soc Sci Med. 2019; 16 (237): 1123- 1129. [DOI:10.1016/j.socscimed.2019.112392] [PMID]

34. Waddell G, Newton M, Henderson I, et al. A FearAvoidance Beliefs Questionnaire (FABQ) and the role of fear-avoidance beliefs in chronic low back pain and disability. Pain. 1993; 52 (2): 157-168. [DOI:10.1016/03043959(93)90127-B]

35. Wells-Federman C, Arnstein P, Caudill M. Nurse-led pain management program: effect on self-efficacy, pain intensity, pain-related disability, and depressive symptoms in chronic pain patients. Pain Management Nursing. 2002;3(4):131-40. [DOI:10.1053/jpmn.2002.127178] [PMID]

36. Jensen MP, Turner JA, Romano JM, et al. The chronic pain coping inventory: Development and preliminary validation. Pain. 1995; 60 (2): 203-216. [DOI:10.1016/03043959(94)00118-X]

37. Asghari A Nichilas MK. An investigation of pain self-efficacy beliefs in Iranian chronic pain patients: A preliminary validation of a translated English-language scale. Pain Med 2009; 10: 619-32.Jennifer B. Levin Kenneth R. Lofland Jeffrey $E$, et al. The relationship between self efficacy and disability in chronic low back pain patients. J Rehab Health. 2000; 2: 19-28. [DOI:10.1111/j.1526-4637.2009.00623.x] [PMID]

38. Barry LC, Guo Z, Kerns RD, et al. Functional self efficacy and pain related disability among older veterans with chronic pain in a primary care setting. Pain. 2003; 104: 131-137. [DOI:10.1016/S0304-3959(02)00471-2]

39. Abid rahmani A, Ghorbanshiroudi S, Kalatbari J, et al. Survey of Depression and Anxiety in Patients with Rheumatoid Arthritis. Jour Guilan Uni Med Sci. 2013; 22 (85): 15-22

40. Bazyari meimand M, Alipour A, Poladi reishahri A, Habibi asgarabadi $M$. Effect of chronic and recurrent pain on the self-management of chronic spinal pain: Moderator role of pain self-efficacy and catastrophic thoughts. Anesthesiology and Pain. 2017;8(1):60-77.

41. Kolivand P, Nazari Mahin A, Jafari R. The Effect of CognitiveBehavioral Therapy on Pain Intensity in Patients with Chronic Pain. The Neuroscience Journal of Shefaye Khatam. 2015;3(3):70-5. [DOI:10.18869/acadpub.shefa.3.3.70]

42. Lombardo ER, Tan G, Jensen MP, et al. Anger management style and associations with self-efficacy and pain in male veterans. Pain. 2005; 6: 765-770. [DOI:10.1016/j. jpain.2005.07.003] [PMID]

43. Mesgarian F, Asghari-Moghaddam, M A, Shairi M R. The 
Role of Self-Efficacy in Predicting Catastrophic Depression in Patients with Chronic Pain. Journal of Clinical Psychology. 2012; 4 (16): 74-83.

44. Besharat MA, Kuchi S, Dehghani M, et al. The moderating role of self-efficacy on the relationship between emotional distress, pain severity and pain-related disability in patients with chronic pain. Journal of Modern Psychological Research. 2011; 6 (21): 44-58.

45. Council JR, Ahern DK, Follick MJ, et al. Expectancies and functional impairment in chronic liw back pain. Pain. 1988; 33: p. 323-31. [DOI:10.1016/0304-3959(88)90291-6]

46. Cleeland C, Portenoy R, Rue M, Mendoza TR, Weller E, Payne $R$, et al. Does an oral analgesic protocol improve pain control for patients with cancer? An intergroup study coordinated by the Eastern Cooperative Oncology Group. Annals of oncology. 2005;16(6):972-80. [DOI:10.1093/ annonc/mdi191] [PMID]

47. Katon W, Sullivan M, Russo J, et al.Depressive symptoms and measures of disability: a proapective study. J Affect Disord. 1999; 27: 245-254. [DOI:10.1016/01650327(93)90048-O]

48. Coyle $\mathrm{CP}$, Santiago MC. Aerobic exercise training and depressive symptomatology in adult with phrsical disability. Arch Phys Med Rehab. 2000; 76: 647-652.
[DOI:10.1016/S0003-9993(95)80634-2]

49. Turner JA, Ersek M, Kemp C. Self-Efficacy for Managing Pain Is Associated With Disability, Depression, and Pain Coping Among Retirement Community Residents With Chronic Pain. Pain. 2005; 6: p. 471-79. [DOI:10.1016/j. jpain.2005.02.011] [PMID]

50. Shirazi Tehrani AR, Mirdrikvand F, Sepahvandi MA. The effectiveness of cognitive - behavioral therapies and model- based therapy in reducing chronic musculoskeletal pain intensity. Clinc Pschol Andishe va Raftar. 2016; 11(44): p. 67-76.

51. Shahin R, Shaeiri MR, Asghari Moghadam MA, et al. etermining the Effectiveness of Cognitive-Behavioral Therapy for Pain Control on Reducing Negative Emotion and Pain Severity in Patients with Chronic Pain. Psycholo achieve. 2011; 18 (2): 1-20.

52. Jafari Y, Peyman N. Effect of Education Program on Students Stress Training, Based on Self-Efficacy Theory. Journal of Health Literacy. 2019;4(1):33-42. [DOI:10.22038/ jhl.2019.40178.1052]

53. A-sghari Moghadam MA. Change the concept of pain over time. CACP. 2015; 13 (2): 165-172. [DOI:10.22038/ jhl.2019.40178.1052] 